\title{
THE ROLE OF PARENTS IN THE TEACHING OF ENGLISH FIRST ADDITIONAL LANGUAGE IN THE RURAL AREA OF LIMPOPO
}

\author{
Masilonyana Motseke, University of South Africa, South Africa
}

\begin{abstract}
Parents, through their communication with their children, play an important role in the linguistic development of these children. The linguistic development of children proceeds from the mastery of the mother tongue to the learning of the second language. The purpose of this study was to determine the role of parents in their children's learning of English First Additional Language (EFAL). The study was conducted at a rural school in the Limpopo Province. The study was qualitative in nature, and an interpretivist approach was followed. Purposive sampling was used to select participants. Eight parents participated in the study. Of the eight parents, seven were female. All the participants were unemployed, and their ages ranged between 22 and 50 years. Semi-structured interviews were used to collect data. The collected data were categorised and themes were identified. It was found that the parents played little or no role in their children's learning of EFAL. The parents were unable to help their children with EFAL homework, to visit the teachers of their children, to monitor the academic (EFAL) progress of their children, and to provide their children with English reading material. It is recommended that parents should be encouraged to visit the school regularly, to check if homework was done and to provide their children with English reading material.
\end{abstract}

Keywords: parental involvement, English second language, rural schools, poverty

\section{INTRODUCTION}

The use of English as a language of business and communication in the world has increased the demand for instruction in English in non-English-speaking countries, with the result that the majority of English teachers in the world are non-native English speakers (Camiciottoli, 2020: 97; Jeon, 2020: 3). When Casale and Posel (2011: 389) compared proficiency in English and income in the disadvantaged areas of South Africa, they found that those who could read and write well in English earned higher incomes than those who could not. The possibility of good employment could be the reason why many parents and the school governing bodies of many government schools have opted for English as both the first additional language and the language of learning and teaching from grade 4 onwards (De Jager, 2017: 117). However, the introduction of English to non-English speaking learners at such an early stage is characterised by many problems. This situation has raised debates around the contextualisation and indigenisation of English in non-English speaking countries, whereby the interdependence between English and the local context is considered (Tabiri, 2016: 593).

The localisation of English implies a serious consideration of the cultural, social, economic and linguistic contexts in the teaching and learning of the English language (McIntosh, Connor \& Gokpinar-Shelton, 2017: 15; Pasassung, 2003: 57). For instance, in South Africa, 
English is the second or third language for many African teachers and learners (Christie, 2010: 5), and this makes the teaching and learning of English difficult in the schools for African children. Hence, the introduction of English to African teachers and learners has to consider these teachers' and learners' deficiencies with regard to the English language. Pasassung (2003: 57) found that the classroom activities in many non-native Englishspeaking settings were marked by the teacher's explanation of grammatical rules and meanings of words. Hence, Pasassung (2003: 58) believes that non-English speaking learners who learn English under difficult and inadequate conditions may only be taught the grammatical knowledge of English, without being expected to be involved in the real use of the language. Therefore, the use of learners' mother tongue in the teaching of English (codeswitching) is important since it accommodates learners who are not proficient in the English language (Howie, Venter and Surette, 2008: 1). Nemati and Taghizadeh (2013: 2479) believe that a good knowledge of the mother tongue is important for the acquisition of English as a second or third language, since the learners use the skills and rules of their mother tongue to learn English. Therefore, the role of parents in helping their children to learn the mother tongue would be a great contribution in the children's learning of English.

The purpose of this study was to investigate the role that parents played in their children's learning of English First Additional Language (EFAL) at a specific school in the Limpopo Province. The research question was: What role do parents play in their children's learning of EFAL in the intermediate phase in the Limpopo Province?

\section{LITERATURE REVIEW}

The language input that children receive at an early age from their parents, or from their teachers in early childcare programmes, plays a crucial role in their linguistic development. This implies that the differences in the home backgrounds of children may bring about differences in their linguistic development. Kwenda, Ntuli and Gwatidzo (2015: 99) state that the linguistic development of children from more affluent families is better than that of children from low-income backgrounds, since children living in poverty are less likely to hear diverse words and syntactically complex language structures than those from middle-class families. Huttenlocher, Waterfall, Vasilyeva, Vevea and Hedges (2010: 345) found that differences in language exposure between the children of low-income families and middleclass families may lead to differences in the academic development of these children, with children from middle-class families achieving better scores than those from low-income families. Nevertheless, communication between parents and their children at an early stage is beneficial to the children's linguistic and academic development.

According to Larson et al. (2020: 159), the role of parents in the learning of languages could be the result of the linguistically responsive and culturally responsive interventions. Linguistically responsive interventions recognise that children possess linguistic strengths that play an important role in language learning (Hoff, 2013: 6). Therefore, linguistically responsive interventions support the development of the home language of the child, and encourage the use of the home language to learn the second language or English (Castro, Páez, Dickinson \& Frede, 2011: 16; Hoff, 2013: 7). Duran, Hartzheim, Lund, Simonsmeier and Kohlmeier (2016: 349) state that the strengthening of children's home language has been shown to lead to strong skills in the learning of English. This implies that the home language can be used alongside English. Linguistically responsive interventions in the home may include book reading, picture sorting, simple instructions and games that can be conducted through the mother tongue, with one or two English words in between (Larson et al., 2020: 
160). Since parents play an important role in the development of the mother tongue, their linguistically responsive interventions could also play an important role in the development of English (or a second language) among children.

Culturally responsive interventions are those interventions that incorporate the values, beliefs, practices, experiences and materials relevant to the cultural backgrounds of children (Larson et al., 2020: 160). For instance, in some cultures, mother-and-child discussions or bookreading activities are characterised by the passing over of information through clear statements, while in other cultures the what, when and why questions and their responses may be of great importance in the mother-and-child discussions or activities (Gay, 2010: 26). Culturally responsive interventions may involve children's culturally informed learning styles (e.g., cooperative vs. competitive learning approaches) and books that emphasise cultural norms for child behaviour (Gay, 2010: 29). In the culturally responsive interventions, codeswitching (using home language to explain events and images presented in English) and 'baby talk' may play a major role as a way of clarifying or emphasising certain statements and ideas (Ismail \& Yusof, 2016: 62). Ismail and Yusof (2016: 62) found that when 'baby talk' was used at school for the learning of the second language, language acquisition became more effective than when the normal way of teaching was used. The culturally responsive interventions that promote the acquisition of language skills in the classroom should consider how to reflect the home culture in the curricula, books and instructions (Larson et al., 2020: 161). In this way, consistency between the home practices and the school practices may be established.

Parents' level of education may have a great impact on the role they can play in their children's learning of English or EFAL. The linguistically responsive and culturally responsive interventions require a certain level of education, since they involve reading, the use of English words and the promotion of certain behaviours. Educated or middle-class parents generally earn higher salaries, work flexible hours and possess knowledge of academic English that they could use to contribute to the education of their children (Kwenda et al., 2015: 99). In addition, educated parents expose their children to English by listening to English radio stations, watching English stories on the television and buying English newspapers and magazines (Christie, 2010: 9). Zahedani, Rezaee, Yazdani, Bagheri and Nabeiei (2016: 133) found that the parents' level of education may influence the efficiency of their child-rearing activities, with higher levels of education promoting behaviour that is acceptable to teachers and lower levels of education promoting tendencies that teachers may dislike. Matsuoka, Nakamuro and Inui (2015: 161) found that college-educated parents tend to employ parenting practices that positively contribute to their children's scholastic performance. According to Statistics South Africa (2011: 20), the number of adults with no formal schooling was the highest among African women and men at $15 \%$ and $11 \%$ respectively, while only less than one percent of white women and men had no formal schooling. The exposure of African people to apartheid over a long period has had a negative impact on education provision for African learners. Factors such as forced removals, lack of schools for African children in certain areas, poor resourcing of schools and child labour contributed negatively to the schooling of African children during the apartheid era (Kgatla, 2015: 122). Although apartheid was officially abolished in 1994, the problems it created, for education in particular, continue to have a negative impact on teaching and learning in township and rural schools, as well as on the intervention and role of parents in the education of their children. 
Some cultural practices of the African people promote negative culturally responsive interventions. For instance, early marriage, initiation or mountain schools and cattle herding have been practised in many African cultures, especially among African people living in rural areas (Mohlaloka, Jacobs \& De Wet, 2016: 22). In addition, girls may not be encouraged to attend school due to the view that they would be married and their biological parents would not benefit from their education (Mohlaloka et al., 2016: 24). In addition, many teenage girls fall pregnant and leave school (Mohlaloka et al., 2016: 24). The situation implies that these girls may not acquire the education and qualifications that could enable them to secure employment and to sustain themselves and their families. According to Larson et al. (2020: 161), culturally responsive interventions that are promoted in the home culture should be reflected in the school curricula, books and instructions, thus creating harmony and continuity between the home and the school. However, early pregnancies, early marriages, initiation or mountain schools and discrimination against girl children create a serious conflict between the home culture and the school culture. The conflict between the home culture and the school culture is not conducive for culturally responsive interventions that promote school education.

The role of both parents is important in the children's language development. Conica, Nixon and Quigley (2020:3) found that the differences in the way mothers and fathers talked to their children at a very early age benefited the children's language development. In addition, the children developed a rich vocabulary diversity that could strengthen their mastery of the first language - which is crucial for the learning of the second language (Conica et al., 2020: 8; Hoff, 2013: 9). However, it is common in South Africa for mothers to bring up children as single parents, without the support of the fathers. Statistics South Africa (2017: 29) found that about $60 \%$ of South African homes were fatherless. The problems facing women-headed families in rural areas include poverty and unemployment, since women are more likely to remain unemployed than men (Business Insider, 2020: 1). The absence of fathers could be a result of unmarried women, and men working in the cities and only coming home once a month (Statistics South Africa, 2011: 29). The implication is that the absence of fathers may have a negative impact on the effectiveness of the linguistically and culturally responsive interventions. Moreover, in the African culture, boys do not readily subject themselves to the control of women, irrespective of the women's ages (Mohlaloka et al., 2016: 28). The situation becomes even more complex when the boy has undergone the initiation ritual or mountain school training, since such boys are viewed as having completed their transition into manhood and women have certain limits in dealing with them (Mohlaloka et al., 2016: 29). This makes the control of the boy child very difficult in cases where there is no father figure.

\section{THEORETICAL FRAMEWORK}

The social development theory of Vygotsky (1978: 56) formed the basis for this study. According to Vygotsky (1978: 56), social interaction plays a fundamental role in the process of cognitive development. Vygotsky (1978: 59) emphasises that social interaction precedes development, or socialisation has to occur first in order for development to take place. According to Vygotsky (1978: 59), every function in the child's cultural development appears twice: first on the social level, and later on the individual level; first between people (interpsychological) and then inside the child (intrapsychological) (Vygotsky, 1978: 57). For example, in the learning of a language, the child's first utterances with peers or adults are for the purpose of communication, but once communication has been mastered, the utterances become internalised and allow 'inner speech', whereby the child can communicate to him- or 
herself (Vygotsky, 1978: 57). This applies equally to voluntary attention, logical memory and the formation of concepts - functions that result from the actual relationships between individuals (Vygotsky, 1978:57). Social development theory involves the process of socialisation, which contributes to the learning process in an individual. This implies that it is only through socialisation with peers or adults that the learning process can occur. Hence, the communication of parents with the child at home, as a form of socialisation, is crucial in the child's language development. In the classroom, language learning occurs when the learner interacts with the teacher and fellow learners (as a form of socialisation). Therefore, the individual child should play an active role in the socialisation process in order for learning to occur faster and more efficiently.

Social development theory is relevant to this study. Social development theory emphasises the socialisation process and its contribution to language development. Parents' communication with their children contributes enormously to the socialisation process. This implies that parents, through communication with their children, play an important role in the children's language development, since socialisation precedes language development. For instance, children develop a good knowledge of the mother tongue through their communication with parents. In cases where the communication between the child and the parent is in English or includes some English words, the parent's contribution to the child's learning of English is phenomenal. Hence, parents could play an important role in their children's development of English or learning of EFAL.

\section{METHODOLOGY}

The study was qualitative in nature, and an interpretivist approach was followed. Qualitative researchers study things in their natural settings, attempting to make sense of and interpret phenomena in terms of the meanings people bring to them (Creswell, 2013: 5). Semistructured interviews were used to collect data. A semi-structured interview is a qualitative method of inquiry that combines a pre-determined set of open questions (questions that prompt discussion) with the opportunity for the interviewer to explore particular themes or responses further (McMillan \& Schumacher, 2010: 33). In this study, an interview schedule was used to ensure that the same order was followed in posing questions to all the participants. Probing was also used to obtain better clarity on information provided. A tape recorder was used, with the permission of the participants (McMillan \& Schumacher, 2010: $35)$.

\section{Participants}

The participants in this study were parents from one school that was situated in a rural area of Limpopo. The selection of parents was purposive, since only parents whose children were in the intermediate phase at the specific school participated in the study. The parents were invited to school for the purpose of the interviews. Eight parents arrived at the school and participated in the study. The parents were labelled using letters of the alphabet, from A to $\mathrm{H}$. All the participants were unemployed, and their ages ranged between 22 and 50 years. Seven of the eight participants were female. 


\section{Data collection and analysis}

The interviews were conducted at the school. Arrangements were made with the different parents to meet at school at different times. The Sepedi language was used to conduct the interviews since the parents were not conversant with English.

A descriptive data analysis approach was followed. The collected data were analysed as follows: categories were determined, and words with similar meanings were placed in the same categories (Winke, 2017: 77). From these categories, patterns emerged, and the patterns led to themes (McMillan \& Schumacher, 2010: 38). The themes were scrutinised in terms of the research question and the purpose of the study (McMillan \& Schumacher, 2010: 44). The reason for this approach was to ensure that the purpose of the study was not ignored or forgotten.

\section{ETHICAL CONSIDERATIONS}

Ethical clearance for this study was obtained from the Ethics Committee of the University of South Africa (Ref: 2017/09/13/90233522/01/MC). Permission to conduct the study at the school was obtained from the Department of Basic Education.

The participants completed forms to give consent for their participation in this study. The participants were informed that their participation in this study was voluntary, and they were free to withdraw from the study at any stage. The participants were also informed that their names were not required, and that the information they provided would be treated with strict confidentiality.

\section{FINDINGS}

The findings were categorised in line with the views of Carey (2015: 275), who states that the categorisation of questions or responses is important for data analysis. Consequently, the following categories were determined:

- helping children with homework and schoolwork;

- school visits;

- lack of monitoring;

- no English at home; and

- English reading material.

\section{Helping children with homework and schoolwork}

All the parents reported that they did not help their children with schoolwork, since they did not know English or formal school English.

Parent B said:

I want to help but I cannot help because of my lack of school [academic] English knowledge. The little English I know cannot be used to help my child with her schoolwork. 
Parent E said:

I cannot speak English. I will be confusing my child if I try to help, because my information will be wrong. I is better when the child works on the information from the teacher.

Although the parents did not help with the actual schoolwork, the majority reported that they advised their children to do their schoolwork, or simply confirmed whether their children did their schoolwork.

Parent A said:

I just make sure that my child does his homework. I always remind him to stop playing outside and to take his books and do his schoolwork.

Parent F said:

Every day before bedtime I ask my child if she has done her schoolwork. Sometimes I insist on seeing it. I only check the date, and if it is that day's date I become satisfied that that day's work was done.

\section{School visits}

All the parents reported that they did not visit the school or their children's EFAL teacher to check their children's progress.

Parent B said:

I am unable to go school due to my church and community engagements. Because I have not heard any problem from the school, I assume that the child is doing well.

Parent F said:

Going to school is not easy, especially for an uneducated person like me. I am scared that I may be embarrassed, or the teacher may ask me something that I do not know, or the teacher may scold me for something that I do not do.

\section{Lack of monitoring}

Only two parents monitored the activities of their children after school, including eating, playing, watching TV and doing schoolwork. However, other parents did not monitor what their children were doing after school or whether they did their homework.

Parent D said:

I make sure that my child plays where I can see her and with children I know, then I call her to watch children's stories on TV before she does her schoolwork. I also tell her when to go to bed. This helps me to teach certain behaviours in the child, and to encourage her to watch stories that will help her with school English, unlike adult stories that may show her adult scenes.

Parent E said:

Per Linguam 2020 36(1):112-124

http://dx.doi.org/10.5785/36-1-860 
I am too busy with my chores, and it is difficult to monitor my child. But I have not heard a complaint that he does not do his schoolwork, so I assume that all is still well.

\section{No English at home}

All the participants reported that they could not speak English, although they could hear it here and there.

Parent G said:

I do not know how to speak English. I worked for employers who spoke Afrikaans during my working days. You were even disliked by the authority if you spoke English. So we did not even try to speak it.

Parent D said:

My [level of] education is very low for English. I can only speak and read Sepedi.

\section{Lack of English reading material}

All the participants reported that they did not have any English reading books, newspapers or magazines at home for children to read.

Parent A said:

We never have books at home. The newspapers and magazines need money, and can only be bought in town or at the big shops. We hardly go to town and to those supermarkets. Moreover, the money we have can hardly cover the basics that we need. We cannot sacrifice it for books and magazines.

Parent H said:

I wish we could have books for our children to read, especially storybooks. But we do not have them, and we cannot afford to buy them.

\section{DISCUSSION}

The results indicate that the parents could not help their children with EFAL schoolwork, because they did not know English. In order for the parents to help their children with EFAL schoolwork, they needed to have knowledge of the English language, including grammar and meanings of words. The reason for the parents' lack of English knowledge could be that they may not have had the opportunity to attend school or to become educated due to the apartheid policies and cultural practices. The apartheid government made it difficult for African children to attend school or access quality education (Kgatla, 2015: 126). In addition, the cultural practices of the African people, such as early marriages and initiation schools, kept many African children away from formal schooling (Mohlaloka et al., 2016: 27). The apartheid policies, as well as the cultural practices of some Africans, had a negative impact on the participants' ability to acquire education and to help their children with EFAL schoolwork. The responses indicate that parents wished to help their children with schoolwork, but were unable to do so. This would have been frustrating for these parents. The parents' inability to help their children with their English schoolwork had a negative impact 
on the socialisation process, particularly the element of English communication. In addition, there was no way of establishing continuity, harmony and relationships between the home and school practices. The lack of English communication between parents and their children implies that parents could not use English to convey certain meanings and behaviours to the child. Therefore, there was no opportunity for linguistically and culturally responsive interventions.

The school visits were also a serious problem for the parents. It is important that parents regularly visit the school to discuss the child's academic progress with the teacher, and to address disciplinary problems that the teacher may observe from the child. However, the parents' failure to visit the school made it difficult for the teacher to notify parents of their children's progress and problems. Studies have indicated that parents' level of education and socioeconomic status play an important role in their involvement in the education of their children (Lemmer, 2012: 92; Von Otter, 2014: 558). Merz (2017: 57) found that teachers were friendlier when they dealt with parents from the middle class, since there was a match between the lifestyles and educational levels of the teachers and those of the middle-class parents. The high rate of unemployment among the participants could be associated with poverty and low levels of education. Therefore, they were not in a position to engage teachers with regard to the academic progress of their children. Hence, they were uncomfortable to visit the school and meet their children's teachers. Meetings between the teachers and parents would not only help to establish relationships between the homes and the school, but would also help parents to know which interventions are required in order to promote the school culture.

The issue of monitoring children's activities after school was also important for EFAL. It is extremely important for parents to know when their children do their homework, when they play, when they watch TV and which TV programmes they watch. Parents who monitor their children may be certain that their children have done their schoolwork, and that they watch TV programmes that help them with their schoolwork and with the knowledge of English. In this study, only two parents checked whether their children did their homework (although they did not check the correctness of the homework). The rest did not check whether homework was done. None of the parents reported monitoring the TV programmes watched by their children. This implies that the majority of the participants did not know whether their children did their schoolwork or not, and whether they watched relevant TV programmes. The parents' survival activities and lack of education could be responsible for the lack of monitoring of their children after school. Nicolson (2015: 2) states that over 12 million South Africans live in extreme poverty and spend most of their time searching for employment or searching for the basic means of survival, such as food, shelter and clothes. In addition, many African parents belong to stokvels, church organisations and social groups, and spend a great deal of time away from home doing work for these structures (Lemmer, 2012: 86). This implies that these parents do not have time to be with their children after school in order to monitor them, to communicate with them and to socialise with them. Therefore, there is no opportunity for linguistically and culturally responsive interventions by parents.

The lack of contact with English at home was another serious problem for the learning of EFAL. The participants' poor education, particularly their lack of English knowledge, implies that their children had no one to talk to or to ask when they were uncertain about something in their EFAL schoolwork. The children could only speak English at school, with their friends or the EFAL teacher. It also implies that there were no opportunities for the children to practise the English language in a relaxed and less intimidating environment like the home, 
and with supportive parents. In cases where English communication between children and their parents is lacking, English channels on the radio and TV would be good measures of exposing children to English at home. However, due to illiteracy or low levels of education, the parents may not have been in a position to ensure that appropriate radio and TV channels were listened to or watched.

The lack of English reading material at home was also a serious setback in the learning of EFAL. The parents' inability to provide their children with English reading material was related to social problems such as poverty and unemployment. The parents reported that the income at their disposal, mostly from the government's social grant, was not enough to buy basics such as food and clothing. Therefore, this income could not be used to buy magazines, newspapers or books for reading. In the absence of English reading material at home, the radio and TV remained valuable sources for supporting the learning of English among children who had these devices at home. However, strict monitoring of TV and radio programmes would be important to ensure that the children benefited from such media. With poor monitoring of the TV and radio programmes watched or listened to by children, the benefit that could be obtained from the availability of TV and radio in the family may be lost. In the case of families that did not have TVs and radios, the lack of reading materials at home implies that the children from such families had no exposure to English after school. The lack of reading material, coupled with the parents' inability to communicate to these children in English, implies that these children's English development was extremely restricted.

\section{CONCLUSION}

The study revealed that learners did not have adequate parental support in the learning of EFAL. The parents did not have the necessary knowledge, income or parenting skills to support their children in the learning of EFAL. Therefore, the children had little or no support outside the school, and depended mainly on the school and teachers for the learning of EFAL. However, rural schools experience serious problems, such as a lack of resources and overcrowding, implying that teachers are also not in a position to adequately support the learners in the learning of EFAL. Therefore, the lack of parental support in the learning of EFAL for intermediate phase learners could have a negative impact on the children's future schooling and employment opportunities.

\section{RECOMMENDATIONS}

The following recommendations can go a long way in helping parents to improve their involvement in the teaching and learning of English:

- Parents should monitor their children's homework and check whether it was done or not.

- Parents should regularly visit the EFAL teacher in order to discuss the role they could play in their children's learning of EFAL.

- Parents should monitor the activities of their children after school, so that they are able to ensure that their children make time for schoolwork.

- Parents should monitor the TV and radio programmes that their children watch or listen to.

\section{REFERENCES}


BUSINESS INSIDER SA. 2020. Police crackdowns on informal traders added to unemployment. Available from https://www.businessinsider.co.za/south-africaunemployment-2020-2 [Accessed: 11 February 2020].

CAMICIOTTOLI, BC. 2020. Using English as a lingua franca to engage with investors: An analysis of Italian and Japanese companies' investor relations communication policies. English for Specific Purposes, 58:90-101. https://doi.org/10.1016/j.esp.2020.01.003

CAREY, MA. 2015. Focus groups. In International Encyclopedia of the Social \& Behavioral Sciences. 274-279. London: Elsevier.

CASALE, D, \& D POSEL. 2011. English language proficiency and earnings in a developing country: The case of South Africa. The Journal of Socio-Economics, 40(4):385-393.

CASTRO, DC, MM PAEZ, DK DICKINSON \& E FREDE. 2011. Promoting language and literacy in young dual language learners: Research, practice, and policy. Child Development Perspectives, 5:15-21. https://doi.org/10.1111/j.1750-8606.2010.00142.x

CRESWELL, JW. 2013. Qualitative inquiry and research: Choosing among five approaches (3rd ed.). Thousand Oaks, CA: Sage.

CHRISTIE, P. 2010. The complexity of human rights in global times: The case of the right to education in South Africa. International Journal of Educational Development, 30(1):311.

CONICA, M, E NIXON \& J QUIGLEY. 2020. Fathers' but not mothers' repetition of children's utterances at age two is associated with child vocabulary at age four. Journal of Experimental Child Psychology, 191:1-12. https://doi.org/10.1016/j.jecp.2019.104738

DE JAGER, T. 2017. Perspectives of teachers on differentiated teaching in multi-cultural South African secondary schools. Studies in Educational Evaluation, 53:115-121.

DURAN, LK, D HARTZHEIM, EM LUND, V. SIMONSMEIER \& TL KOHLMEIER. 2016. Bilingual and home language interventions with young dual language learners: A research synthesis. Language, Speech, and Hearing Services in Schools, 47(4):347-371. https://doi.org/10.1044/2016_LSHSS-15-0030

GAY, G. 2010. Culturally responsive teaching: Theory, research, and practice. New York: Teachers College Press.

HOFF, E. 2013. Interpreting the early language trajectories of children from low-SES and language minority homes: Implications for closing achievement gaps. Developmental Psychology, 49:4-14. https://doi/org/10.1037/a0027238

HOWIE, S, E VENTER \& S VAN STADEN. 2008. The relationship between English second language proficiency and mother tongue in non-native English speakers in South Africa. Paper presented at the Third IEA International Research Conference, Taipei, Chinese Taipei.

HUTTENLOCHER, J, H WATERFALL, M VASILYEVA, J VEVEA \& LV HEDGES. 2010. Sources of variability in children's language growth. Cognitive Psychology, 61:343-365. https://doi.org/10.1016/j.cogpsych.2010.08.002

ISMAIL, A \& N YUSOF. 2016. Readability of ESL picture books in Malaysia. Journal of Nusantara Studies (JONUS), 1(1):60-70.

JEON, M. 2020. Native-English speaking teachers' experiences in East-Asian language programs. System, 88. https://doi.org/10.1016/j.system.2019.102178

KGATLA, ST. 2015. Forced removals and migration: a theology of resistance and liberation in South Africa. Missionalia, 41(2):120-132. https://doi.org/10.7832/41-2-9

KWENDA, $\mathrm{P}, \mathrm{M}$ NTULI \& $\mathrm{T}$ GWATIDZO. 2015. Temporal developments in intergenerational transmission of education: Case for black South Africans. Research in Social Stratification and Mobility, 42:96-113. 
LARSON, LA, LM CYCYK, JJ CARTA, CS HAMMER, M BARALT, Y UCHIKOSHI, ZG AN \& C WOOD. A systematic review of language-focused interventions for young children from culturally and linguistically diverse backgrounds. Early Childhood Research Quarterly, 50:157-178. https://doi.org/10.1016/j.ecresq.2019.06.001

LEMMER, E.M. 2012. Who's doing the talking? Teacher and parent experiences of parentteacher conferences. South African Journal of Education, 32:83-96.

MATSUOKA, R, M NAKAMURO \& T INUI. 2015. Emerging inequality in effort: A longitudinal investigation of parental involvement and early elementary school-aged children's learning time in Japan. Social Science Research, 54:159-176.

MCINTOSH, K, U CONNOR \& E GOKPINAR-SHELTON. 2017. What intercultural rhetoric can bring to EAP/ESP writing studies in an English as a lingua franca world. Journal of English for Academic Purposes, 29:12-20. https://doi.org/10.1016/j.jeap.2017.09.001

MCMILLAN, JH \& S SCHUMACHER. 2010. Research in education: Evidence-based inquiry (7th ed.). New Jersey: Pearson.

MERZ, J. 2017. Socioeconomic status: A potential challenge for parental involvement in schools. The Delta Kappa Gamma Bulletin: Journal for Professional Educators, 83(3):58-62.

MOHLALOKA, SMB, L JACOBS \& NC DE WET. 2016. Insights from traditional initiation teachers (Basuwe) on the influence of male traditional initiation (lebollo) on the behaviour of school boys. Perspectives in Education, 34(2):19-32.

NEMATI, M \& M TAGHIZADEH. 2013. Exploring similarities and differences between L1 and L2. International Research Journal of Applied and Basic Sciences, 4(9):2477-2483.

NICOLSON, G. 2015. South Africa: Where 12 million live in extreme poverty. Daily Maverick. Available from https://www.dailymaverick.co.za/article [Accessed: 12 June 2018].

PASASSUNG, N. 2003. Teaching English in an 'acquisition-poor environment': An ethnographic example of a remote Indonesian EFL classroom. Sydney: Department of Linguistics, University of Sydney.

STATISTICS SOUTH AFRICA. 2011. Statistical release (revised). Pretoria: Government Printer.

STATISTICS SOUTH AFRICA. 2017. Statistical release (revised). Pretoria: Government Printer.

TABIRI, MO. 2016. Teaching Francophone learners English vocabulary without resorting to the use of L1 and L2. Procedia - Social and Behavioral Sciences, 232:591-599.

VON OTTER, C. 2014. Family resources and mid-life level of education: A longitudinal study of the mediating influence of childhood parental involvement. British Educational Research Journal, 40(3):555-574.

VYGOTSKY, LS. 1978. Mind in society. Cambridge, MA: Harvard University Press.

WINKE, P. 2017. Using focus groups to investigate study abroad theories and practice. System, 71:73-83.

ZAHEDANI, ZZ, R REZAEE, Z YAZDANI, S BAGHERI \& P NABEIEI. 2016. The influence of parenting style on academic achievement and career path. Journal of Advances in Medical Education \& Professionalism, 4(3):130-134. 


\section{ACKNOWLEDGEMENTS}

I wish to sincerely thank all the parents who participated in this study, as well as the University of South Africa for the funding of the project.

\section{BIOGRAPHICAL NOTE}

Prof Masilonyana Motseke is an associate professor in the Department of Adult Education and Youth Development at the University of South Africa. His research interests include the teaching of English to disadvantaged learners, adult education and teacher stress.

Email: motsemj@unisa.ac.za 